\title{
Decrease anesthetic requirements and analgesics postop, in patients undergoing laparoscopic cholecystectomy: premedication with acetaminophen versus intravenous ketorolac
}

\begin{abstract}
Objective: To compare the effects of premedication with intravenous paracetamol versus ketorolac, in decreasing intraoperative anesthetic and postoperative opioid analgesics requirements in patients undergoing laparoscopic cholecystectomy.

Method: To be determined intraoperative opioid requirements, pain and analgesic requirements in the postoperative period in 100 healthy patients undergoing laparoscopic cholecystectomy. The selection was in two groups: group 1: premedicated with paracetamol and group 2: with ketorolac, both administered intravenously 30 minutes prior to surgery.

Results: There weren't statistically significant differences between groups with respect to intraoperative remifentanil consumption (group 1: $0.0739 \pm 0.016$, group 2: $0.0741 \pm$ 0.018 ). The number of patients in group 2 had values of VAS $>4$ points $(22.4 \%)$ was lower than in group $1(28.6 \%)$, but without statistically significant difference. Of the patients who merited reinforcements postoperative opioids, most merited a single reinforcement and application of analgesics during hospitalization prevailed between 3 and 12 hours, without significant differences between groups. No adverse effects were observed in the study sample.
\end{abstract}

Conclusion: Paracetamol 1g IV placed preoperatively decreased anesthetic requirements and the need for postoperative analgesics, similar to preoperative administration of ketorolac $30 \mathrm{mg} \mathrm{IV}$.

Keywords: premedication, paracetamol, ketorolac, opioids, laparoscopic cholecystectomy, postoperative pain
Volume 5 Issue I - 2016

Medina V Adrián, Novoa Z Luis M

Department of Anesthesiology, General Hospital East "Dr. Domingo Luciani”, Venezuela

Correspondence: Adrián José Medina Vera, Department of Anesthesiology, General Hospital East $\square$ Dr. Domingo Luciani, C.I. 17.459.184.,Venezuela, Tel 04I6-3064924,

Email veraadm@gmail.com

Received: November 15, 2015 | Published: June 13,2016
Abbreviations: NSAID, nonsteroidal anti-inflammatory; COX, cyclooxygenase; CNS, central nervous system; G, gram; Mg, milligram; ASA, American society of anesthesiologists; M1, Milliliter; $\mathrm{Kg}$, kilogram; $\mathrm{O}_{2}$, oxygen; $\mathrm{FiO}_{2}$, fraction of inspired oxygen; $\mathrm{Mg}$, microgram; $\mathrm{SO}_{2}$, oxygen saturation; EVA, visual analog scale; $\mathrm{BMI}$, body mass index

\section{Introduction}

Laparoscopic surgery is a technique that today offers numerous advantages, being a less invasive allows faster recovery with a lower rate of morbidity and mortality. However, the use of the pneumoperitoneum interfere with the anesthetic, forcing the anesthesiologist to use anesthetic techniques that not only provide optimal surgical conditions but a wide patient safety and should minimize the risk of hypertension or hypotension, arrhythmias, hypoxia, hypercapnia pulmonary embolism, heart failure, aspiration and pneumothorax; and try to avoid the side effects of drugs used, reducing the requirements thereof to provide the patient a fast and pleasant awakening, and better postoperative pain control with minimal side effects. ${ }^{1-3}$

NSAIDs inhibit the activity of the COX enzyme, which is responsible for the production of prostaglandins and thromboxanes from arachidonic acid. This decrease of prostaglandin which makes them responsible for the therapeutic effects and adverse reactions. ${ }^{4,5}$ Ketorolac is a NSAID family of heterocyclic derivatives of acetic acid with potent analgesic and mild anti-inflammatory action. Your best effect is in pain with an important inflammatory component, including postoperative pain, trauma or burns, incidental pain or exacerbations of chronic pain; however, it is undesirable for long-term use due to side effects that, especially after the fifth day of treatment, it is only left to rescue acute pain. ${ }^{6-8}$

Paracetamol is a metabolite of phenacetin, increasing the pain threshold COXs inhibition in the CNS, however not inhibited in peripheral tissues reason lacks anti-inflammatory activity. Intravenous acetaminophen has been associated with short-term treatment of moderate pain, especially following surgery and for the shortterm treatment of fever; also allows a lower dose of opioids and is generally associated with other molecules to multimodal analgesia in the treatment of postoperative pain. For these reasons it has recently emerged as an excellent option, but research is still required to establish their benefits. ${ }^{9-13}$

Hence, to study the effects of paracetamol, which could replace the use of other NSAIDs or opioids with fewer adverse effects, we compare the anesthetic effects in reducing intraoperative and postoperative analgesic requirements of paracetamol $1 \mathrm{~g}$ intravenous ketorolac $30 \mathrm{mg}$, both administered as a preoperative medication in patients for laparoscopic cholecystectomy.

\section{Methods}

After approval by the ethics committee of the institution and obtain written informed consent, 100 patients aged between 18 and 55 years, ASA I-II scheduled for laparoscopic cholecystectomy were included 
in the study. We excluded those patients with kidney or liver disease, a history of gastrointestinal bleeding, allergy medications used, longer operating time of 2 hours and where there has been conversion to open surgery technique.

Patients randomly assigned to each group. The mixture administered to group 1 consisted of $1 \mathrm{~g}$ intravenous paracetamol injectable solution with a total volume of $100 \mathrm{ml}$, group 2 was $30 \mathrm{mg}$ ketorolac further dilution in $0.9 \%$ saline to a total volume of $100 \mathrm{ml}$. All were given over a period not less than 15 minutes, 30 minutes prior to surgery, and prepared by an anesthesiologist who was not involved in the study.

Ten minutes before the surgical procedure, patients were sedated with midazolam $0.05 \mathrm{mg} / \mathrm{kg}$, ranitidine $1 \mathrm{mg} / \mathrm{kg}, 0.2 \mathrm{mg}$ metoclopramide / $\mathrm{kg}$ and dexamethasone $0.2 \mathrm{mg} / \mathrm{kg}$. Once in the operating room, patients were placed monitoring type ASA II standard with cardioscope, pulse oximetry, blood pressure noninvasively, capnography and analyzer inspired gas and expired, using two monitors previously calibrated, intended for data collection study. After the denitrogenation, anesthesia was induced with intravenous drugs the following: Fentanyl $2 \mu \mathrm{c} / \mathrm{kg}$, lidocaine $1 \% 1 \mathrm{mg} / \mathrm{kg}$, $1 \%$ Propofol $2 \mathrm{mg} / \mathrm{kg}$ rocuronium bromide and $0.6 \mathrm{mg} / \mathrm{kg}$. The maintenance of anesthesia was performed with $\mathrm{O}_{2}$ and air to a total volume of 2 liters with $\mathrm{FiO}_{2} 0.6$; $\mathrm{CAM}$ isoflurane to 0.5 as measured by gas analyzer; and remifentanil infusion at a dilution of 10.mu.g / $\mathrm{ml}$, administered by infusion pump (OT - 701, JMS).

Prior to the surgical incision, mixed with $10 \mathrm{ml}$ and $50 \mathrm{mg}$ Bupivacaine is saline $0.9 \%$ for a $0.25 \%$ concentration was prepared; which ran the surgical team for local infiltration in points trocar placement 15 minutes before incision. The reversal of neuromuscular blockade was performed with Neostigmine $0.04 \mathrm{mg} / \mathrm{kg}$ and atropine $0.02 \mathrm{mg} / \mathrm{kg}$ and after extubation; the patient was transferred to the recovery area. After the surgery the total amount of opioid used during the procedure was recorded on the instrument.

The patient remained in the recovery area for a period of four hours where heart rate, noninvasive blood pressure and $\mathrm{SO}_{2}$ was monitored, and postoperative according EVA hours from their entry into the area assessed pain.

It was reinforced analgesia morphine $40 \mu \mathrm{g} / \mathrm{kg}$ was observed in case more than 4 points in case EVA and postoperative nausea and vomiting are evidenced Ondansetron $0.1 \mathrm{mg} / \mathrm{kg}$ was administered and were recorded on the instrument. The day after the surgery, the patients were seen in the area of hospitalization and were questioned about the first time requested analgesics, after its entry into the area. This result was also recorded in the instrument

The average and standard deviation for continuous variables were calculated; in the case of nominal variables, their frequencies are calculated and verified the normality of porcentajes. Her scale variables as sphericity test Shapiro-Wilks. Comparison of type scale variables between groups was based on the Student $t$ test for independent samples. For nominal variables, the Pearson chi-square test was applied to measure independencia. She considered significant if $p$ value $<0.05$. Data were analyzed with JMP-SAS version 11 .

\section{Results}

It was found that the groups were statistically equivalent with respect to sex, age and BMI of patients, which would be verified that no adjustments based on these variables in trying to analyze the variables involved to prove the hypothesis of the study (Table 1).
Table I Sample characteristics according to groups

\begin{tabular}{|c|c|c|c|}
\hline Variables & Paracetamol & Ketorolaco & \\
\hline $\mathrm{N}$ & 50 & 50 & \\
\hline Age & $41 \pm 10$ & $38 \pm 11$ & \\
\hline IMC & $26,4 \pm 2,3$ & $25,6 \pm 2,8$ & \\
\hline Sex & & & \\
\hline Male & $72,0 \%$ & 38 & $76,0 \%$ \\
\hline Female & $28,0 \%$ & 12 & $24,0 \%$ \\
\hline $\begin{array}{l}\text { *Age: } t=1,514(p=0,133) \\
\dagger \text { IMC: } t=1,646(p=0,103) \\
\ddagger \text { Sex: } c 2=0,052(p=0,820)\end{array}$ & & & \\
\hline
\end{tabular}

Of the 100 patients that were sampled in the study, one was excluded from conversion of the surgical technique and another prolonged surgical time; so the analyzes were performed based on 98 individuals.

Remifentanilointraoperatorio dose did not differ significantly between groups, being similar in both (Table 2).

With regard to postoperative pain was greater the number of individuals who filed less than 4 points in the ketorolac group EVA, although there was no statistically significant difference regarding the number of patients who were given acetaminophen, being the manifestation of similar pain in both cases.

The number reinforcement used opioids postoperatively did not differ between the groups, the number of patients who merited reinforcements was similar in both cases, being statistically superior individuals not merited its administration in both groups.

The time when these reinforcements merited postoperatively was lower in the group of patients who received paracetamol; however, this did not mean a significant change to the group receiving ketorolac. It is concluded that the time he spent in receiving the reinforcement was similar; this difference could not be due to sample size in the sub analysis, that is, only 14 subjects were compared in the paracetamol group and 11 in ketorolac, as only these reinforcements merited.

The application of analgesics in hospital was frequent in the range 3 to 12 hours, considering the events between 3-6 hours and 6-12 hours, being similar in both groups. Separating individuals receiving reinforcement recovery not (Tables $3 \& 4$ ), was also similar analgesic requirements in the range of 3 to 12 hours, without significant differences between groups

\section{Discussion}

The multimodal analgesia based on non-opioid drugs such as acetaminophen and NSAIDs have provided a route for the reduction in consumption of intraoperative anesthetic, postoperative pain and decreased need for opioid drugs which have been linked to increased incidence of adverse effects. ${ }^{14}$ Waleed et al., ${ }^{15}$ found that 1 $\mathrm{g}$ of paracetamol IV preoperative significantly decreases sevoflurane consumption during general anesthesia, if compared with the results obtained in this study, can infer that such reduction is comparable to the use of premedication ketorolac $30 \mathrm{mg}$ IV which is considered a highly effective NSAIDs in the treatment of pain, as anesthetic requirements of patients receiving paracetamol and ketorolac were similar. This implies that, by decreasing concentrations of remifentanil, along with a reduction in the balance already established isoflurane anesthesia with opioid lower incidence of adverse effects and complications of the anesthetics used such as bradycardia, hypotension, respiratory depression, nausea , hyperalgesia and skeletal muscle rigidity, ${ }^{16,17}$ further reducing hospital costs by reducing drug use; this makes the multimodal analgesic paracetamol and / or ketorolac take importance on this topic. 
Table 2 Features anesthetic variables

\begin{tabular}{|c|c|c|c|c|}
\hline Variables & \multicolumn{2}{|c|}{ Paracetamol } & \multicolumn{2}{|c|}{ Ketorolaco } \\
\hline $\mathrm{N}$ & \multicolumn{2}{|c|}{49} & \multicolumn{2}{|l|}{49} \\
\hline Intraoperative dose of remifentanil ( $\mu \mathrm{g} / \mathrm{kg} / \mathrm{min})$ & \multicolumn{2}{|c|}{$0,0739 \pm 0,0160$} & \multicolumn{2}{|c|}{$0,074 \mid \pm 0,018$} \\
\hline \multicolumn{5}{|l|}{ Postoperative pain } \\
\hline EVA $<4$ points & 35 & $71,4 \%$ & 38 & $77,6 \%$ \\
\hline EVA $>4$ points & 14 & $28,6 \%$ & II & $22,4 \%$ \\
\hline \multicolumn{5}{|l|}{ \# Reinforcements Opioid Postoperatively } \\
\hline Any & 35 & $71,4 \%$ & 38 & $77,6 \%$ \\
\hline One & 12 & $24,5 \%$ & 11 & $22,4 \%$ \\
\hline Of & 1 & $2,0 \%$ & 0 & $0,0 \%$ \\
\hline Three & I & $2,0 \%$ & 0 & $0,0 \%$ \\
\hline Recovery time when merit reinforcement ( $\mathrm{min})$ & \multicolumn{2}{|c|}{$49 \pm 25$} & \multicolumn{2}{|c|}{$68 \pm 36$} \\
\hline \multicolumn{5}{|l|}{ Request Analgesic in Hospitalization } \\
\hline I a 3 hours & I & $2,0 \%$ & 0 & $0,0 \%$ \\
\hline 3 a 6 hours & 20 & $40,8 \%$ & 21 & $42,9 \%$ \\
\hline 6 a 12 hours & 27 & $55,1 \%$ & 27 & $55,1 \%$ \\
\hline 12 a 18 hours & I & $2,0 \%$ & l & $2,0 \%$ \\
\hline \multicolumn{5}{|c|}{ * Intraoperative dose of remifentanil: $t=0,058(p=0,954)$} \\
\hline \multicolumn{5}{|c|}{ † postoperative pain: $c 2=0,483(p=0,487)$} \\
\hline \multicolumn{5}{|c|}{$¥ \#$ postoperative opioid reinforcements: $c 2=2,167(p=0,539)$} \\
\hline \multirow{2}{*}{\multicolumn{5}{|c|}{$\S$ Strengthening recovery when warranted: $t=1,550(p=0,135)$}} \\
\hline & & & & \\
\hline
\end{tabular}

Table 3 Moment contingency table analgesic request in hospitalization (group receiving no reinforcement) * Groups

\begin{tabular}{|c|c|c|c|}
\hline \multirow{2}{*}{ Request Analgesic in Hospital } & \multicolumn{2}{|l|}{ Groups } & \multirow{2}{*}{-Total } \\
\hline & Paracetamol & Ketorolaco & \\
\hline$I-3$ hours & I & 0 & I \\
\hline $3-6$ hours & 12 & 17 & 29 \\
\hline $6-12$ hours & 21 & 21 & 42 \\
\hline $12-18$ hours & I & 0 & I \\
\hline $18-24$ hours & 0 & 0 & 0 \\
\hline Total & 35 & 38 & 73 \\
\hline
\end{tabular}

Table 4 Moment contingency table analgesic request in hospitalization (group receiving reinforcement) * Groupps

\begin{tabular}{|c|c|c|c|}
\hline $\begin{array}{l}\text { Request analgesic in } \\
\text { Hospitalization }\end{array}$ & $\begin{array}{l}\text { Groups } \\
\text { paracetamol }\end{array}$ & Ketorolaco & Total \\
\hline I -3 hours & 0 & 0 & 0 \\
\hline $3-6$ hours & 8 & 3 & II \\
\hline $6-12$ hours & 6 & 7 & 13 \\
\hline $12-18$ hours & 0 & I & 1 \\
\hline $18-24$ hours & 0 & 0 & 0 \\
\hline Total & 14 & II & 25 \\
\hline
\end{tabular}

Regarding postoperative pain, about $75 \%$ of patients were managed with mild pain or pain in the recovery area. For several years, it is known that paracetamol and ketorolac, are high quality drugs in the treatment of postoperative pain; A multicenter study by Torres et al concluded that acetaminophen 1 g every 4 - 6 days provides good analgesia in postoperative pain within 24 hours after surgery: ${ }^{12}$ Prospective studies by Salihogluet al., ${ }^{18}$ Gholamreza et al., ${ }^{19}$ \& Singla et al., ${ }^{20}$ found that paracetamol is an effective analgesic in postoperative pain of patients who were undergoing laparoscopic cholecystectomy, surgery of the lower limbs and hip arthroplasty respectively; and 2 meta-analyzes prepared by Macario et al., ${ }^{21} \&$ De Oliveira et al., ${ }^{22}$ confirmed that the use of acetaminophen is effective in reducing postoperative pain in different surgical procedures with lower incidence of adverse effects. Also, Singla et al., ${ }^{23}$ by another study found that a dose of ketorolac $31.5 \mathrm{mg}$ intranasally is an effective drug in the treatment of postoperative pain when used in abdominal surgery. De Oliveira et al., ${ }^{24}$ takes another meta - analysis evaluating the use of a single dose ketorolac in peri - operative to prevent postoperative pain and concluded that the same dose of $60 \mathrm{mg}$ is an effective adjuvant multimodal analgesia regimes postoperario reduce pain and have little evidence concerns when used in doses of $30 \mathrm{mg}$; this I differ in part with our results in which the use of ketorolac $30 \mathrm{mg}$ IV, but administered preoperatively, proved sufficient to decrease the incidence of postoperative pain in $75 \%$ of patients who underwent laparoscopic cholecystectomy made It could have been influenced since the benefit of preemptive analgesia in these patients, although partially higher in the ketorolac group took advantage, there were no statistically significant differences between the 2 groups.

The use preemptive analgesia to reduce analgesic requirements and adverse drug reactions, is not new and increasingly have been studied with the techniques and drugs that take advantage of this property, where our group studies (paracetamol and ketorolac) have already been reviewed previously having enough satisfactory results. ${ }^{25,26}$

The rest of the sample studied had moderate to severe pain, so they merited reinforcements analgesic morphine $0.4 \mathrm{mg} / \mathrm{kg}$, of which most adequately responded to the administration of a single dose, this data also showed no statistically significant differences between individuals who were given paracetamol or ketorolac and match various studies that have compared the use of paracetamol, desketoprofeno, ketorolac and metamizol lornoxicam, among other NSAIDs and $\mathrm{COX}_{2}$; that have demonstrated the decreased consumption of morphine for postoperative pain management. ${ }^{27-31}$ 
When reviewing this subgroup of patients who presented with elevated EVA, we note that they found related to greater surgical manipulation or the presence during the intervention traces of blood or bile secretion in the abdominal cavity that required the use of saline to wash thereof, which is associated with higher levels of pain in individuals who undergo this type of intervention..$^{32,33}$

The time when these 25 patients had values greater than 4 points EVA was approximately 60 minutes of being in the recovery area, being smaller group for paracetamol (acetaminophen $49 \pm 25,68 \pm$ 36 ketorolac; difference statistically not significant). This could be related to that prior to the start of the painful process, yet it had the effect of fentanyl is administered prior to intubation, the elimination half-life is 2-6 hours and its analgesic effect can last up to 2 hours being much more powerful than the paracetamol and ketorolac, which could have kept the postoperative analgesia until the disappearance of the effect of this opioid. ${ }^{34}$

During hospitalization was observed that patients merited reinforcement analgesic mostly between 3 and 12 hours after admission to the area, being similar in both study groups even if the individual had received the backing of morphine during recovery, this It could be because the half-life of paracetamol IV is from 4-6 pm and ketorolac IV 6-8 hours, so that by passing its analgesic effect was necessary to strengthen the use of these medications in hospital, most likely patients received opioids also maintained the same time because analgesia IV morphine analgesia provides up to 12 hours after administration. ${ }^{35}$ Only one patient had postoperative nausea and vomiting, however, it was excluded from the study for prolonged surgical time, this event being absent in patients who were part of the sample; watching so that decreasing the use of opioids in the intra and postoperative, were able to reduce the incidence of nausea and vomiting, as expected by leveraging the analgesic effect of other medicines as was the paracetamol and ketorolac in this case, that occur with less incidence of these. ${ }^{36}$

As we can see from our results, the use of paracetamol $1 \mathrm{~g}$ IV was equivalent to $30 \mathrm{mg}$ of ketorolac IV in the subjects studied; however, being a NSAID ketorolac with significant adverse effects that limit their use over time, it forces us to look more friendly to maintain the desired analgesic effect treatment options and are taking acetaminophen field in this matter, being easier passage orally and shown to be as effective as tramadol, metamizol, Propacetamol, desketoprofeno, diclofenac, parecobix and as we demonstrated in our study with ketorolac, making it an important tool for the anesthesiologist. ${ }^{37-40}$

For future research, we recommend evaluating the behavior of paracetamol and ketorolac in combination with other analgesics families in different age populations; this would allow us to open our knowledge on the subject of multimodal analgesia and preemptive analgesia, so we recommend continuing these studies. ${ }^{41-43}$

\section{Conclusion}

In conclusion, Premedication with paracetamol 1g IV reduced opioid requirements in the intra and postoperative similar to ketorolac $30 \mathrm{mg}$ IV, without incidence of adverse events in the sample, making it an effective analgesic for pain management postoperative.

\section{Acknowledgements}

We want to give special thanks to all teachers and residents of Anesthesiology body, without which there would have been possible methodology and data collection for the study raised and which have always been with us during the course of the investigation.
We thank the entire body of surgeons and nurses, who worked with us to obtain materials and sample needed to perform this special graduation project. Thank you very much to all the people who were involved with us and who made this possible.

\section{Conflicts of interest}

The authors declare no conflict of interest.

\section{Funding}

None.

\section{References}

1. Rivera J. Controversias en anestesia para cirugía laparoscópica. Rev Mex Anestesiol. 2007;30(Suppl 1):139-141.

2. Espinoza GL, Zavalza JF, Monroy OP, et al. Colecistectomías laparoscópicas realizadas en Unidad de Cirugía Ambulatoria. Cir Gen. 2011;33(2):104-110.

3. Chandrashekaraiah MM, Upadya M, Jayachandran SP, et al. Effects of clonidine premedication on hemodynamic changes during laparoscopic cholecystectomy. Appl Cardiopulm Pathophysiol. 2011;15:91-98.

4. Kesimci E, Gümüş T, İzdeş S, et al. Comparison of efficacy of dexketoprofen versus paracetamol on postoperative pain and morphine consumption in laminectomy patients. Ăgri. 2011;23(4):153-159.

5. Kamal M, Abdullah C, Yeasmeen S, et al. Postoperative analgesia after lumbar disc surgery:a comparison between ketorolac and opioid. JBSA. 2010;23(2):56-61.

6. Katlauskas S, Oliva BE, Paula I. Evaluation of ketorolac compared to ketorolac plus dipyrone in post-operative analgesia of videolaparoscopic cholecystectomy. Einstein. 2009;7(2 pt 1):190-193

7. Cohen MN, Christians U, Henthorn T, et al. Pharmacokinetics of singledose intravenous ketorolac in infants aged 2-11 months. Anesth Analg. 2011;112(3):655-660.

8. Aftab S, Rashdi S, Akhtar J, et al. Comparison of intravenous ketorolac with diclofenic for postoperative analgesia. J Surg Pak (Pakistan). 2008;13(2):62-66

9. Ohnesorge $\mathrm{H}$, Bein B, Hanss R, et al. Paracetamol versus metamizol in the treatment of postoperative pain after breast surgery:a randomized, controlled trial. Eur J Anaesthesiol. 2009;26(8):648-653.

10. Arici S, Gurbet A, Türker G, et al. Preemptive analgesic effects of intravenous paracetamol in total abdominal hysterectomy. A $\breve{g r i}$. 2009;21(2):54-61.

11. Oscier CD, Milner QJ. Peri-operative use of paracetamol. Anaesthesia. 2009;64(1):65-72.

12. Torres LM, Peñuela FM, Castilla G, et al. Estudio observacional sobre el dolor postoperatorio leve o moderado:Evaluación del tratamiento con paracetamol IV-estudio EOPEP. Rev Soc Esp Dolor. 2008;15(4):219_ 27.

13. Oscier C, Bosley N, Milner Q. Paracetamol - a review of three routes of administration. 2008;23:112-114.

14. Elvir-Lazo O, White $\mathrm{P}$. The role of multimodal analgesia in pain management after ambulatory surgery. Curr Opin Anesthesiol. 2010;23(6):697-703.

15. Abdelmageed W, Al Taher W. Preoperative paracetamol infusion reduces sevoflurane consumption during tiroidectomy under general anesthesia with spectral entropy monitoring. Egyptian J Anaesth. 2014;30(2):115122

16. Bingel U, Wanigasekera V, Wiech $\mathrm{K}$, et al. The effect of treatment expectation on drug efficacy:imaging the analgesic benefit of the opioid remifentanil. Sci Transl Med. 2011;3(70):1-9. 
17. Panzer O, Moitra V, Sladen R. Phamacology of sedative-analgesic agents:dexmedetomidine, remifentanil, ketamine, volatile anesthetics, and the role of peripheral mu antagonists. Crit Care Clin. 2009;25(3):451-469.

18. Salihoglu Z, Yildirim M, Demiroluk S, et al. Evaluation of intravenous paracetamol administration on postoperative pain and recovery characteristics in patients undergoing laparoscopic cholecystectomy. Surg Laparosc Endosc Percutan Tech. 2009;19(4):321-323.

19. Khalili G, Janghorbani M, Saryazdi H, et al. Effect of preemptive and preventive acetaminophen on postoperative pain score:a randomized, double-blind trial of patients undergoing lower extremity surgery. J Clin Anesth. 2013;25(3):188-192.

20. Singla N, Hale M, Davis J, et al. IV Acetaminophen:Efficacy of a Single Dose for Postoperative Pain After Hip Arthroplasty:Subset Data Analysis of 2 Unpublished Randomized Clinical Trials. Am J Ther. 2015;22(1):2-10.

21. Macario A, Royal M. A Literature Review of Randomized Clinical Trials of Intravenous Acetaminophen (Paracetamol) for Acute Postoperative Pain. Pain Pract. 2011;11(3):290-296.

22. De Oliveira G, Castro-Alves L, McCarthy R. Single Dose Systemic Acetaminophen to Prevent Postoperative Pain:A Meta-analysis of Randomized Controlled Trials. Clin J Pain. 2015;31(1):86-93.

23. Singla N, Singla S, Minkowitz H, et al. Intranasal ketorolac for acute postoperative pain. Curr Med Res Opin. 2010;26(8):1915-1923.

24. De Oliveira G, Agarwal D, Benzon H. Perioperative Single Dose Ketorolac to Prevent Postoperative Pain:A Meta-Analysis of Randomized Trials. Anesth Analg. 2012;114(2):424-433.

25. Yasmin R, Akhtaruzzaman AK, Chandra P, et al. Pre-emptive analgesia for postoperative pain relief in children-role of paracetamol. Journal BSA. 2005;18(1\&2):9-16.

26. In Hwa $\mathrm{L}$, Chi-Yun $\mathrm{S}$, Jong $\mathrm{H}$, et al. The preemptive analgesic effect of ketorolac and propacetamol for adenotonsillectomy in pediatric patients. Korean J Anesthesiol. 2009;57(3):308-313.

27. Lee SY, Lee WH, Lee EH, et al. The Effects of paracetamol, ketorolac, and paracetamol plus morphine on pain control after thyroidectomy. Korean J Pain. 2010;23(2):124-130.

28. Maund E, McDaid C, Rice S, et al. Paracetamol and selective and nonselective non-steroidal anti-inflammatory drugs for the reduction in morphine-related side-effects after major surgery:a systematic review. Br J Anaesth. 2011;106(3):292-297.

29. Oreskovic Z, Bicanic G, Hrabac P, et al. Treatment of postoperative pain after total hip arthroplasty:comparison between metamizol and paracetamol as adjunctive to opioid analgesics-prospective, doubleblind, randomised study. Arch Orthop Trauma Surg. 2014;134(5):631636.

30. Tunali Y, Akçil E, Dilmen O, et al. Efficacy of Intravenous Paracetamol and Dexketoprofen on Postoperative Pain and Morphine Consumption After a Lumbar Disk Surgery. J Neurosurg Anesthesiol. 2013;25(2):143147.
31. Korkmaz O, Tunali Y, Cakmakkaya O, et al. Efficacy of intravenous paracetamol, metamizol and lornoxicam on postoperative pain and morphine consumption after lumbar disc surgery. Eur $J$ Anesthesiol. 2010;27(5):428-432.

32. Krishnakumar M. Latrogenic bile duct injuries during laparoscopic cholecystectomy - early management and the role of endoscopy and surgery. The Sri Lanka J Surg. 2011;29(2):87-88.

33. Seo YK, Lee HJ, Ha TK, et al. Effect of Normal Saline Irrigation on Attenuation of Shoulder Tip Pain and on $\beta$-Endorphin Levels After Laparoscopic Cholecystectomy. J Laparoendosc Adv Surg Tech A. 2012;22(4):311-314.

34. Logneker D, Brown D, Newman M, et al. Anestesiología. 1st ed. McGraw Hill, USA; 2008. p. 869-896;2183-2185.

35. McNicol E, Tzortzopoulou A, Cepeda M, et al. Single-dose intravenous paracetamol or propacetamol for prevention or treatment of postoperative pain:a systematic review and meta-analysis. Br J Anaesth. 2011;106(6):164-175.

36. Apfel C, Turan A, Souza K, et al. C. Intravenous acetaminophen reduces postoperative nausea and vomiting:A systematic review and metaanalysis. Pain. 2013;154(5):677-689.

37. Durak P, Yağar S, Uzuner A, et al. Postoperative pain therapy after laparoscopic cholecystectomy:paracetamol versus diclofenac. Agri. 2010;22(3):117-120.

38. Uysal HY, Takmaz SA, Yaman F, et al. The efficacy of intravenous paracetamol versus tramadol for postoperative analgesia after adenotonsillectomy in children. J Clin Anesth. 2011;23(1):53-57.

39. Kela M, Umbarkar S, Sarkar M, et al. Comparative Study of Efficacy of IV Paracetamol vs IV Tramadol for Postoperative Pain Relief After Cardiac Surgery. Bombay Hosp J. 2011;53(3):582-586.

40. Brodner G, Gogarten W, Van Aken H, et al. Efficacy of intravenous paracetamol compared to dipyrone and parecoxib for postoperative pain management after minor-to-intermediate surgery:a randomised, double-blind trial. Eur J Anesthesiol. 2011;28(2):125-132.

41. Elseify ZA, El-Khattab SO, Khattab AM, et al. Combined parecoxib and I.V. paracetamol provides additional analgesic effect with better postoperative satisfaction in patients undergoing anterior cruciate ligament reconstruction. Saudi J Anaesth. $2011 ; 5(1): 45-49$.

42. Ong C, Seymour R, Lirk P, etal.Combining Paracetamol(Acetaminophen) with Nonsteroidal Antiinflammatory Drugs:A Qualitative systematic Review of Analgesic Efficacy for Acute Postoperative Pain. Anesth Analg. 2010;110(4):1170-1179.

43. Hannam J, Andreson B, Mahadevan M, et al. Postoperative analgesia using diclofenac and acetaminophen in children. Pediat Anesth. 2014;24(9):953-961. 